Article

\title{
Hydrogen Sorption and Reversibility of the $\mathrm{LiBH}_{4}-\mathrm{KBH}_{4}$ Eutectic System Confined in a CMK-3 Type Carbon via Melt Infiltration
}

\author{
Filippo Peru ${ }^{1}$, SeyedHosein Payandeh ${ }^{2,3}{ }^{[}$, Georgia Charalambopoulou ${ }^{1}{ }^{(}$, \\ Torben R. Jensen ${ }^{2}(D$ and Theodore Steriotis $1, *(D)$ \\ 1 National Centre for Scientific Research "Demokritos", Ag. Paraskevi Attikis, 15341 Athens, Greece; \\ f.peru@inn.demokritos.gr (F.P.); gchar@ipta.demokritos.gr (G.C.) \\ 2 Interdisciplinary Nanoscience Center (iNANO) and Department of Chemistry, University of Aarhus, \\ Langelandsgade 140, DK-8000 Aarhus C, Denmark; Seyedhosein.Payandeh@empa.ch (S.P.); \\ trj@chem.au.dk (T.R.J.) \\ 3 Empa, Swiss Federal Laboratories for Materials Science and Technology, 8600 Dübendorf, Switzerland \\ * Correspondence: t.steriotis@inn.demokritos.gr; Tel.:+30-210-650-36-14
}

Received: 2 March 2020; Accepted: 19 March 2020; Published: 31 March 2020

\begin{abstract}
Metal borohydrides have very high hydrogen densities but their poor thermodynamic and kinetic properties hinder their use as solid hydrogen stores. An interesting approach to improve their functionality is nano-sizing by confinement in mesoporous materials. In this respect, we used the $0.725 \mathrm{LiBH}_{4}-0.275 \mathrm{KBH}_{4}$ eutectic mixture, and by exploiting its very low melting temperature (378 K) it was possible to successfully melt infiltrate the borohydrides in a mesoporous CMK-3 type carbon (pore diameter $\sim 5 \mathrm{~nm}$ ). The obtained carbon-borohydride composite appears to partially alleviate the irreversibility of the dehydrogenation reaction when compared with the bulk $\mathrm{LiBH}_{4}-\mathrm{KBH}_{4}$, and shows a constant hydrogen uptake of $2.5 \mathrm{wt} \%-3 \mathrm{wt} \%$ for at least five absorption-desorption cycles. Moreover, pore infiltration resulted in a drastic decrease of the decomposition temperature (more than $100 \mathrm{~K}$ ) compared to the bulk eutectic mixture. The increased reversibility and the improved kinetics may be a combined result of several phenomena such as the catalytic action of the carbon surface, the nano-sizing of the borohydride particles or the reduction of irreversible side-reactions.
\end{abstract}

Keywords: hydrogen storage; complex hydrides; nanoconfinement; borohydrides; porous carbons

\section{Introduction}

Within the efforts to reduce $\mathrm{CO}_{2}$ emissions and introduce alternatives to fossil fuels, hydrogen appears as one of the most promising energy carriers. However, the practical use of such a low density gas implies a series of challenges mainly pertaining to the storage of a sufficient amount of hydrogen in order to offer a viable solution against the conventional fossil fuels; e.g., more than $5 \mathrm{~kg}$ of stored hydrogen is needed for vehicular applications to match the typical $500 \mathrm{~km}$ autonomy [1-3]. Even if the well-known technology of compressed hydrogen represents an attractive approach, it doesn't reach the volumetric/gravimetric density targets, whereas the high pressures involved ( 700 bar) are an important issue for safety [4]. Due to the possibility of achieving higher hydrogen density, storage in the solid state seems to be a highly advantageous option from different perspectives [5-9]. Among the various materials that have been considered for this purpose, metal borohydrides are particularly interesting as hydrogen storage media $[10,11]$. For instance $\mathrm{LiBH}_{4}$ contains $18.5 \mathrm{wt} \%$ of hydrogen [12], while $13.8 \mathrm{wt} \%$ can be released by its decomposition to $\mathrm{LiH}, \mathrm{B}$ and $\mathrm{H}_{2}$ [13-15]. However, despite their great hydrogen content, alkali and alkali earth borohydrides are generally characterized by high stability and slow kinetics of reaction, reflected in high decomposition 
temperatures and poor cyclability [16-19]. The dehydrogenation temperature of borohydrides can be reduced through different routes; cation substitution and phase transformation but also increase of the hydride surface area through, e.g., the contact with an external surface, are some of the most widely studied approaches [20-24]. The combined effect of cation substitution and phase (from solid to liquid) transition on the dehydrogenation temperature is particularly evident on borohydride eutectic mixtures, such as that of $\mathrm{LiBH}_{4}$ and $\mathrm{KBH}_{4}$, which are the subject of this work. This mixture, investigated systematically by Ley et al. in 2014, [25] has the lowest melting temperature ( 378 K) for the composition $0.725 \mathrm{LiBH}_{4}-0.275 \mathrm{KBH}_{4}$. The introduction of different cations changes the atomic distances in the lattice, influencing the decomposition temperature. At the same time, the occurrence of a solid to liquid phase transition also facilitates the dehydrogenation [22]. However, by itself, the bulk material still has a high dehydrogenation temperature (the main hydrogen release occurs above $573 \mathrm{~K})$, accompanied with poor kinetics as well as irreversibility [26]. In general, drastic improvements of the hydrogenation/dehydrogenation kinetics of borohydrides have been reported as a consequence of nanosizing, commonly obtained through their high-energy ball milling, by reducing the crystallites dimensions and improving the gas diffusion [27]. A drawback of this approach is the re-aggregation of the produced nanoparticles that increase, again, in size during sorption cycles, thus slowly going back to the initial bulk material condition.

For this reason, the stabilization of the nanoscaled material can be achieved by encapsulating the hydrides in porous, e.g., carbon-based scaffolds, thus protecting the nanoparticles in the limited size of the pores [28-30]. The decomposition of pure $\mathrm{LiBH}_{4}$ apart from $\mathrm{H}_{2}$ produces diborane $\left(\mathrm{B}_{2} \mathrm{H}_{6}\right)$, a fraction of which can react with $\mathrm{LiBH}_{4}$, generating stable closoboranes [31-33]. In all cases, there is a loss of capacity, either due to a loss of boron in the gas phase, or due to the high stability of closoboranes. Apart from protection against aggregation, small pores could additionally play a fundamental role in avoiding the release of diborane or the formation of stable closoboranes (or other clusters) that limit the rehydrogenation and reversibility of the borohydrides [34]. Moreover, the presence of the carbon material itself and the intimate contact with the high surface of the scaffold could give rise to catalytic effects or an increase of the thermal conductivity of the composite, and therefore facilitate the dehydrogenation reaction [35-38]. In general, $\mathrm{H}_{2}$ storage and release in borohydrides involves the transfer of significant amounts of heat, which has to be rapid in order to address practical applications (e.g., fast refuelling). Due to their good heat conductivity performance, nanostructured carbons (e.g., graphene) have been applied as additives, for instance, in the case of $\mathrm{MgH}_{2}$ storage systems [39]. Carbonaceous materials, among many available porous scaffolds, also represent a particularly optimal choice due to their inherent inertness and thermal stability, which allows treatment at high temperatures without severely affecting the structure of the material as well as of the encapsulated hydride. Moreover, the (typically) low density of carbon structures and the possibility to shape them into high pore volume materials allows the confinement of large amounts of hydrides without increasing too much the mass of the composite. Finally, the possibility to synthesize materials with tuneable pore size allows the investigation, and thus a better understanding, of the influence of pore size on the confined hydride materials. For all these reasons, the confinement of $\mathrm{LiBH}_{4}$ and $\mathrm{KBH}_{4}$ eutectic mixtures in a high surface nanoporous carbon appears to be an approach of significant interest for the research of solid state hydrogen storage materials [40]. To the best of our knowledge, to date such carbon-based composites have been studied for hydrogen storage purposes only by Roedern et al. [26]. In that work, a $\mathrm{LiBH}_{4}-\mathrm{KBH}_{4}$ eutectic mixture was melt infiltrated in a carbon aerogel with large pore size (approximately $25 \mathrm{~nm}$ ) and the composite system was only tested up to three sorption cycles. In the present work, we have combined a $\mathrm{LiBH}_{4}-\mathrm{KBH}_{4}$ eutectic mixture with an ordered mesoporous CMK-3 type carbon, with small and almost uniform pores (average diameter of about $5 \mathrm{~nm}$ ). CMK-3 materials comprise carbon nanorods that are arranged in a 2D hexagonal pattern and they are interconnected with carbon strands. The space between the rods is the ordered mesopore system, while depending on synthesis conditions the rods themselves may have a noticeable amount of disordered micropores $(<2 \mathrm{~nm})$. This particular type of carbon material shows both high surface area and pore volume, 
allowing the confinement of substantially large borohydride quantities but also facilitating surface interactions [41]. The behaviour of the $\mathrm{LiBH}_{4}-\mathrm{KBH}_{4} / \mathrm{CMK}-3$ composite material was compared with the bulk $\mathrm{LiBH}_{4}-\mathrm{KBH}_{4}$ eutectic mixture; all materials were subjected to the same series of treatments in order to shed light to the contribution of the carbon scaffold on the hydrogen storage properties of the nanoconfined borohydrides.

\section{Materials and Methods}

The CMK-3 type carbon was obtained through a nanocasting procedure, according to a modified version of the original synthesis method described by Ryoo et al. [41] using 2D hexagonal SBA-15 silica (Claytec Inc, East Lansing, MI, USA) as a template. The synthesis involves the impregnation of the silica template with a saturated aqueous solution of a carbon precursor, sucrose in our case. Unlike the procedure of Ryoo et al. that involves two impregnation steps, we impregnated the silica three times. The material obtained based on this procedure has a slightly lower surface area and pore volume, but a narrower pore size distribution compared to CMK-3 type materials prepared by the standard synthesis protocol. The impregnated sucrose was then slowly carbonized by heating the sample at first up to 373 $\mathrm{K}$ for $6 \mathrm{~h}$ and then at $433 \mathrm{~K}$, overnight (heating ramps of $10 \mathrm{~K} / \mathrm{min}$ ). The brown, partially carbonized sample was again impregnated with diluted sucrose solutions and carbonized following the same procedure. After three impregnation/carbonization steps, the sample was pyrolyzed at $1173 \mathrm{~K}$ for 6 $\mathrm{h}$ in a tubular furnace under a constant stream of nitrogen. The fully carbonized sample was then washed with a $40 \%$ solution of hydrofluoric acid, dissolving the silica template. Centrifugation was also employed in order to eliminate any trace of silica and hydrofluoric acid; the carbon as obtained was filtrated with abundant water and ethanol. The final product was then dried overnight in a furnace at about $393 \mathrm{~K}$. The carbon was then further thermally treated in a tubular furnace at $973 \mathrm{~K}$ under inert atmosphere, in order to eliminate the oxygen functional groups commonly present on the surface of the carbon material and thus reduce the possibility of interaction with the confined borohydrides. Before further use, carbon samples were evacuated under $523 \mathrm{~K}$ in order to eliminate any trace of air or moisture trapped into the pores.

The bulk eutectic $\mathrm{LiBH}_{4}-\mathrm{KBH}_{4}$ mixture (denoted hereafter as $\mathrm{LiK}$ ) was prepared starting from $\mathrm{LiBH}_{4}\left(95 \%\right.$, Sigma-Aldrich, St. Louis, MO, USA) and $\mathrm{KBH}_{4}$ (97\%, Sigma-Aldrich, St. Louis, MO, USA) in accordance with references $[25,26]$ and with a molar ratio of $\mathrm{LiBH}_{4}$ and $\mathrm{KBH}_{4}$ equal to $0.725: 0.275$, obtaining a system with a melting temperature of $378 \mathrm{~K}$. The two components were mixed first manually with a pestle and mortar and then mechanically, in order to obtain a system as homogeneous as possible. The mechanochemical treatment was performed with a planetary mill (PULVERISETTE 4, Fritsch GmbH, Idar-Oberstein, Germany) using a tungsten carbide jar with internal volume of $80 \mathrm{~mL}$ and $10 \mathrm{~mm}$ diameter spheres from the same material; the powder-to-balls weight ratio was 1:30 [42]. The milling process consisted of $5 \mathrm{~min}$ of milling at $400 \mathrm{rpm}$ followed by $2 \mathrm{~min}$ of pause, in order to avoid the overheating and decomposition of the material during milling. The process was repeated for a total of 240 min of milling ( 48 cycles). All the handling was carried out within a glove box, under argon atmosphere $\left(\mathrm{O}_{2}\right.$ and $\mathrm{H}_{2} \mathrm{O}$ concentrations $\left.<0.5 \mathrm{ppm}\right)$ in order to avoid any decomposition.

The LiK/CMK-3 composite material was synthesised by infiltrating the carbon scaffold with a certain amount of LiK corresponding to $60 \%$ of the total pore volume (TPV) of CMK-3 (considering that the density of the $\mathrm{LiK}$ mixture is $0.86 \mathrm{~g} / \mathrm{cm}^{3}$ ). The infiltration was performed by mixing manually the carbon and LiK powders (weight ratio CMK-3-LiK 1.59:1) in the glove box, under argon atmosphere to obtain a homogeneous mixture, which was then transferred to a high-pressure stainless-steel reactor. The reactor was then attached to a custom-made high-pressure volumetric sorption apparatus, evacuated at room temperature and consequently pressurized to $\sim 100$ bar of $\mathrm{H}_{2}$; this overpressure was used in order to avoid any decomposition reactions during the next step. The reactor was finally heated from room temperature to $398 \mathrm{~K}$ with a heating rate of $3 \mathrm{~K} / \mathrm{min}$ and kept at isothermal conditions ( $398 \mathrm{~K}$ ) for $30 \mathrm{~min}$, in order to let the molten hydrides penetrate into the porous structure of the carbon scaffold. 
The effectiveness of the infiltration was assessed through both powder X-ray diffraction (PXRD) and $\mathrm{N}_{2}$ adsorption/desorption measurements at $77 \mathrm{~K}$ by evaluating the differences in the diffraction patterns and pore volume before and after melt infiltration. The PXRD analysis was performed using a Smart Lab X-ray diffractometer (Rigaku Corporation, Tokyo, Japan), with a Cu source $(\lambda=1.54 \AA)$. Moreover, the morphology of the composite material was studied with the Gentle Beam mode of a JSM 7401F (JEOL Ltd, Akishima, Tokyo, Japan) Field Emission scanning electron microscope (SEM).

The $\mathrm{N}_{2}$ adsorption/desorption isotherms at $77 \mathrm{~K}$ were measured on a volumetric gas adsorption analyser (Autosorb-1-MP, Quantachrome Instruments, Boynton Beach, FL, USA). Prior to measurement, the samples were appropriately outgassed under high vacuum $\left(10^{-6} \mathrm{mbar}\right)$. The Brunauer-Emmett -Teller (BET) area values were calculated following the BET consistency criteria (ISO 9277:2010), whereas pore size distributions were deduced by using the adsorption $\mathrm{N}_{2}$-carbon QSDFT (Quenched Solid Density Functional Theory) kernel assuming slit/cylinder pore model. The TPV was calculated at $\mathrm{P} / \mathrm{P}_{0}=0.98$.

The decomposition temperatures, the hydrogen uptake and the cyclability of the different materials (bulk LiK and LiK/carbon composites) were studied with temperature programmed desorption experiments coupled with mass spectrometry (TPD/MS) as well as cyclic volumetric dehydrogenation/hydrogenation measurements.

The TPD/MS measurements were performed in a custom-made setup. The sample, contained in a quartz cell, was heated in a furnace up to $973 \mathrm{~K}$ with a heating ramp of $5 \mathrm{~K} / \mathrm{min}$ under a constant flow of argon $(80 \mathrm{~mL} / \mathrm{min})$ used as a carrier. The outlet of the sample cell was continuously sampled by an Omnistar GSD 301 O1 (Pfeiffer Vacuum Technology AG, Aßlar, Germany) quadrupole mass spectrometer ( $\mathrm{m} / \mathrm{z}$ values of 2, 4, 15-18, 23-28, 32, 44, 79, 80 were monitored).

The hydrogen sorption capacity and cyclability of the materials were studied with a custom-made manometric apparatus based on Sievert's method, i.e., using the pressure difference in a known volume in order to calculate the amount of gas exchanged with the sample. The analysed materials were placed in a stainless-steel reactor connected to a thermostat-equipped manifold; the pressure was monitored by an 870 B type Baratron manometer (MKS Instruments Inc, Andover, MA, USA). The experiment comprised 5 cycles of dehydrogenation/hydrogenation under a backpressure of high purity hydrogen $(99.9999 \%)$. Dehydrogenation was triggered by heating the sample up to $773 \mathrm{~K}$ with a ramp of $3 \mathrm{~K} / \mathrm{min}$ and maintaining it at this temperature for $4 \mathrm{~h}$. The whole procedure was carried out under a starting hydrogen backpressure of $\sim 1.5$ bar. The rehydrogenation step was achieved by thermal treatment at $673 \mathrm{~K}$ under 100 bar of pure hydrogen. The reaction temperature was reached with a fast ramp of $5 \mathrm{~K} / \mathrm{min}$, followed by an isothermal step of $12 \mathrm{~h}$.

\section{Results}

The PXRD pattern of the bulk LiK mixture (Figure 1) shows the presence of a crystalline structure, with diffraction peaks relative to both $\mathrm{LiBH}_{4}$ and $\mathrm{KBH}_{4}$ but also to the $\mathrm{LiK}\left(\mathrm{BH}_{4}\right)_{2}$ compound, in accordance with literature [43]. All diffraction peaks completely disappear in the case of the LiK/CMK-3 composite material, indicating the absence of crystalline borohydrides outside the pores of the carbon scaffold after infiltration. SEM studies of LiK/CMK-3 (Figure 1b) confirm the above, as although the typical macroscopic elongated structure of CMK-3 is observed, the particles appear rather structureless (i.e., filled); negligible amounts of $\mathrm{LiK}$ is observed externally (note that the volume ratio of $\mathrm{LiK} /$ carbon is $0.72 / 0.83$ ).

The alteration of the porous structure of the carbon scaffold upon melt infiltration was studied by $\mathrm{N}_{2}$ adsorption/desorption isotherms at $77 \mathrm{~K}$ shown in Figure 2a. The analysis of the respective data for the pristine CMK-3 type carbon gave a BET area of $1250 \mathrm{~m}^{2} / \mathrm{g}$, a TPV of $1.2 \mathrm{~cm}^{3} / \mathrm{g}$, and a narrow pore size distribution centred at $4.6 \mathrm{~nm}$ (Figure $2 \mathrm{~b}$ ). The melt infiltration with $\mathrm{LiK}$ led to a significant change of the pore properties. Indeed, the LiK/CMK-3 material exhibited a BET area of $490 \mathrm{~m}^{2} / \mathrm{g}$ and a $\mathrm{TPV}$ of $0.5 \mathrm{~cm}^{3} / \mathrm{g}$ (both calculated on a pure carbon basis). 


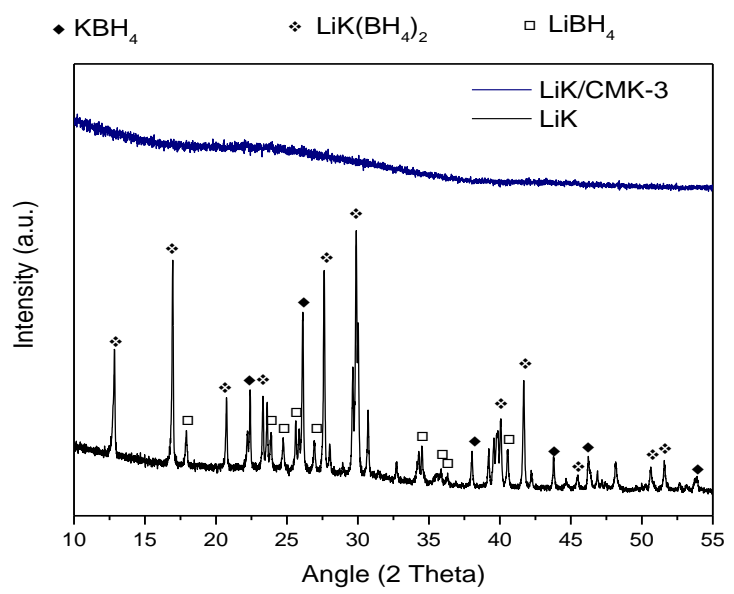

(a)

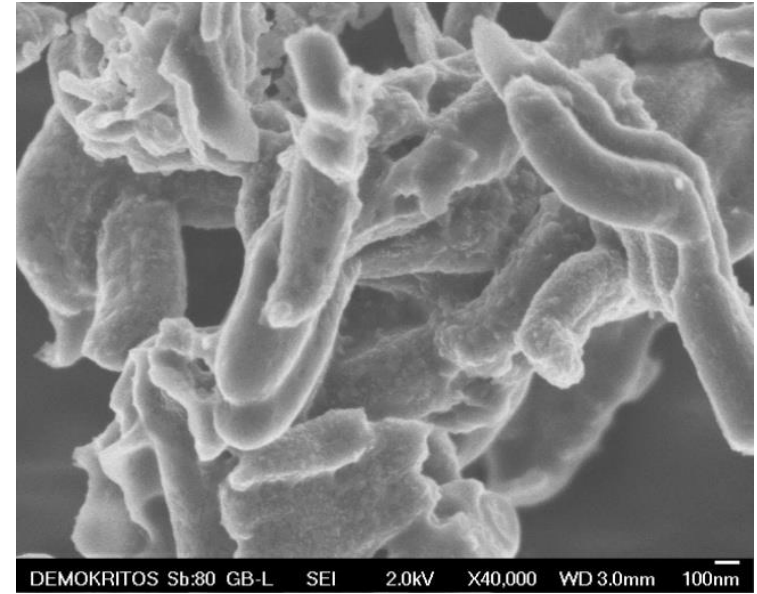

(b)

Figure 1. (a) PXRD pattern of the bulk LiK mixture (black line) and LiK/CMK-3 composite (blue line). Highlighted peaks relative to: $\mathrm{KBH}_{4}(\diamond), \mathrm{LiK}\left(\mathrm{BH}_{4}\right)_{2}(\star)$ and $\mathrm{LiBH}_{4}(\square)$. (b) Scanning electron microscope (SEM) picture of LiK/CMK-3 composite.
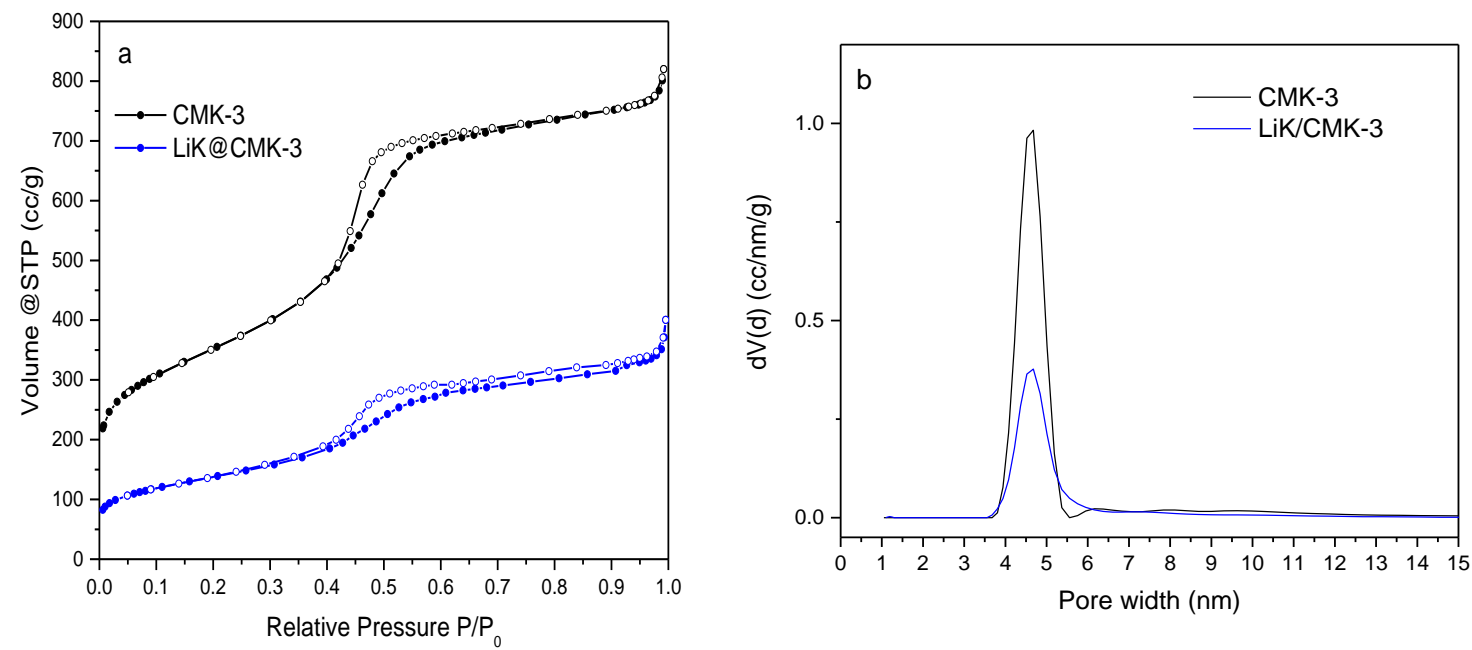

Figure 2. (a). $\mathrm{N}_{2}$ adsorption/desorption isotherms at $77 \mathrm{~K}$ on the pristine CMK-3 carbon (black) and on LiK/CMK-3 composite (blue). (b). Pore size distribution of CMK-3 carbon (black) and LiK/CMK-3 composite (blue).

On the other hand, TPD/MS measurements (Figure 3) showed that upon heating, hydrogen is the only gas released by both the bulk LiK and the LiK/CMK-3 composite, as no trace of diborane was detected. Most importantly, a drastic decrease of the decomposition temperatures of more than $100 \mathrm{~K}$ for the main dehydrogenation peak is observed for the composite when compared with the bulk material. The pure LiK eutectic mixture starts releasing small quantities of hydrogen at $543 \mathrm{~K}$, gradually increasing the amount released until the main desorption peak at about $743 \mathrm{~K}$; this is followed by another intense peak at $\sim 823 \mathrm{~K}$. The several smaller side peaks imply a multistep decomposition process. In contrast, the thermal decomposition of the LiK/CMK-3 sample practically depicts only one main desorption reaction, with secondary shoulder peaks. Nevertheless, this single desorption feature appears on a clearly lower temperature compared to the bulk LiK mixture; the melt infiltrated sample starts releasing hydrogen at about $450 \mathrm{~K}$, but the main decomposition is detected at $\sim 633 \mathrm{~K}$. 


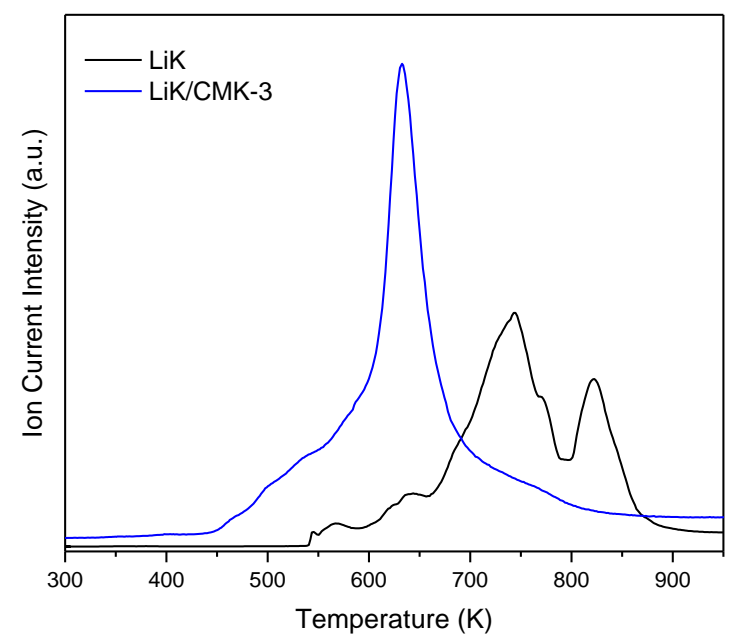

Figure 3. Temperature programmed desorption with mass spectrometry (TPD/MS) results for bulk LiK mixture (black) and LiK/CMK-3 composite (blue).

Besides the dehydrogenation temperatures, which appear drastically reduced after melt infiltration, another fundamental aspect is the cyclability of the materials and the amount of hydrogen uptake at each cycle. The sorption capacity of the materials tested on the custom made manometric apparatus showed that the LiK/CMK-3 material can reach a certain degree of cyclability never achieved before. It should be noted that, since $\mathrm{KBH}_{4}$ is not supposed to decompose, the maximum amount of $\mathrm{H}_{2}$ released from the bulk LiK mixture is $9.5 \mathrm{wt} \%$. Moreover, as mentioned before, the $\mathrm{LiBH}_{4}$ decomposition is usually incomplete (producing $\mathrm{LiH}, \mathrm{B}$ and $\mathrm{H}_{2}$ ); a maximum of $7.2 \mathrm{wt} \%$ is expected in this case.

As shown in Figure 4a, the pure LiK eutectic mixture released in the first dehydrogenation cycle about $3.6 \mathrm{wt} \%$. However, this percentage drastically drops at every cycle and reaches about $0.9 \mathrm{wt} \%$ at the fifth dehydrogenation cycle, highlighting the irreversibility of the pure LiK system as already known. A much better performance is obtained with the LiK/CMK-3 composite, however. As shown in Figure $4 \mathrm{~b}$, the composite released about $6.7 \mathrm{wt} \%$ of hydrogen (calculated over the respective LiK mass) during the first dehydrogenation. Furthermore, in this case, the hydrogen released decreases drastically after the first dehydrogenation, but it stabilises right after the second cycle, releasing consistently more than $2.6 \mathrm{wt} \%$ of hydrogen in the subsequent cycles.

LiK Bulk

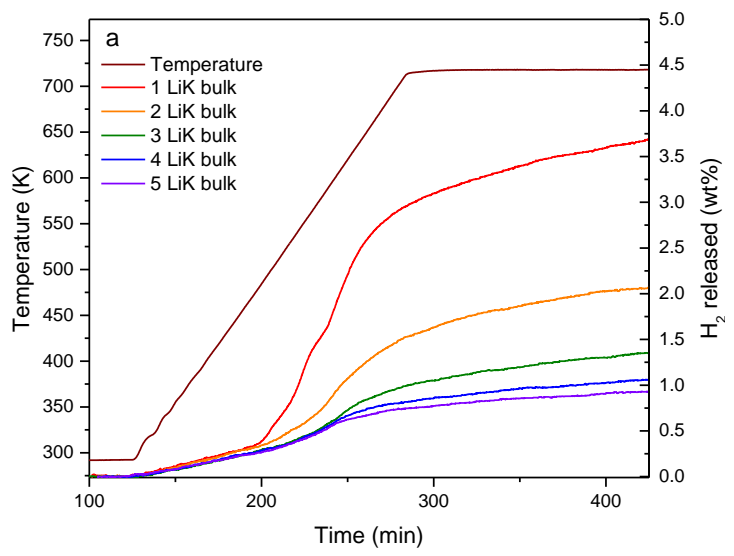

LiK/CMK-3

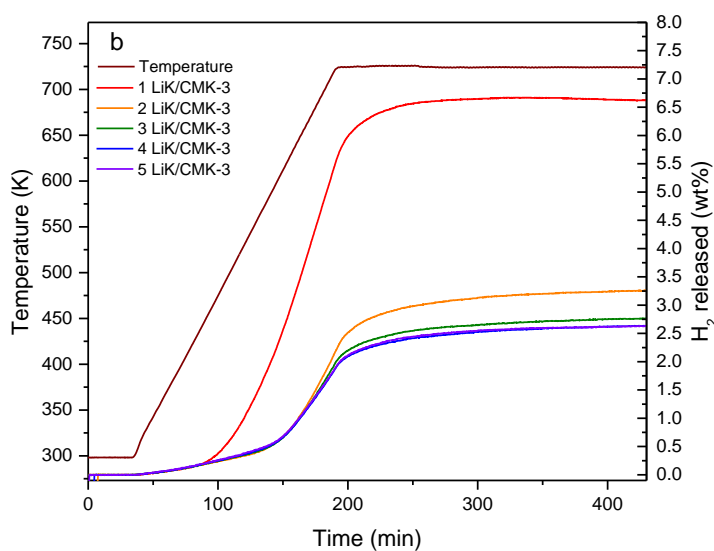

Figure 4. Kinetics of cycling (a). Bulk LiK (b). LiK/CMK-3 composite.

\section{Discussion}

The comparison of the PXRD patterns of the bulk LiK and the LiK/CMK-3 composite (and the disappearance of all the diffraction peaks relative to the borohydrides in the latter case) indicates the 
absence of crystalline hydrides outside of the pores, supporting our hypothesis that the whole hydride phase resides inside the pores of the carbon scaffold [44].

A further confirmation of the successful infiltration of the LiK material within the CMK-3 porous structure was provided by the study of the pore properties of the system before and after the melt infiltration. It should be noted at this point that the results presented have been normalized to pure carbon basis (i.e., the reduction of surface area and pore volume due to the "dead-weight" of LiK is not considered). In particular, the reduction of the TPV by almost $58 \%$ in the case of the LiK/CMK-3 composite shows that almost the whole amount of LiK used permeated inside the carbon pores rendering part of the porous network inaccessible to $\mathrm{N}_{2}$. Despite the significant reduction of pore volume, the pore size distributions of the pristine and melt infiltrated CMK-3 carbons (Figure $2 \mathrm{~b}$ ) are centred on similar sizes. This suggests that the LiK mixture was infiltrated in a way that a number of pores (pertaining to $58 \%$ of the TPV) were completely filled while the rest of the pore network remained practically unaltered. This has been observed and reported in the literature before [29] and is compatible with the extremely open and highly interconnected pore network of CMK-3 (where pore mouth blocking is highly unlike) combined with the self-affinity of the borohydride phase. In other words, the liquid borohydride phase is non-wetting and penetrates in the pores as a front rather than spreading as a film, thus filling more and more pore space during infiltration. This partial pore filling is also suggested by the minute, yet observable high pressure hysteresis that is developed after infiltration.

The effect of the carbon scaffold on the decomposition of the infiltrated LiK is particularly visible from the TPD-MS results; the decrease of the decomposition temperatures is drastic, with the LiK/CMK-3 decomposing at much lower temperatures (more than $100 \mathrm{~K}$ ) than the bulk LiK material. A similar effect was also observed for several borohydrides (and mixtures) (e.g., [45]) but also for LiK confined in a larger pore carbon scaffold [26]. This effect could be due to a "thermodynamic" shift of the decomposition temperature caused by, e.g., the increased surface tension of LiK nanoparticles under confinement, but it is most probably of "kinetic" nature. In brief, smaller particle sizes increased surface to volume ratios leading to shorter diffusion paths and thus faster kinetics. It should be mentioned, nevertheless, that a catalytic effect of the carbon surface as well as enhanced heat transfer at the nanoscale are also possible.

The manometric cycling measurements also revealed additional important information on the performance of the bulk and confined borohydrides. The first release experiment confirms the TPD-MS results, since the bulk LiK material exhibits a multi-stage release pattern with very slow kinetics, while the LiK/CMK-3 composite reveals a faster and quite smooth release curve. Additionally, the amount of $\mathrm{H}_{2}$ released from the LiK/CMK-3 composite is much higher than the bulk (note that in both cases the $\mathrm{wt} \%$ values refer to the LiK weight). Keeping in mind that both the bulk LiK and the LiK/CMK-3 materials were pre-treated under the same conditions, we may argue that part of the bulk material was deactivated, while LiK was "protected" when melted in the presence of the carbon. The second release cycle of the bulk and infiltrated LiK shows that, in both cases, the capacity dropped by roughly $50 \%$ from the first cycle. However, upon further cycling, a different behaviour is observed. The bulk material capacity is constantly decreasing; it drops below $1 \mathrm{wt} \%$ at the fifth cycle. On the other hand, the confined LiK reaches a constant capacity of around $2.5 \mathrm{wt} \%-3 \mathrm{wt} \% \mathrm{H}_{2}$, exhibiting a practically reversible character (up to at least the fifth cycle). As discussed before, the enhanced performance of the nanoconfined LiK may be associated with many factors, however, the increased stability of the system is probably related with the protection offered by the porous network since particle aggregation is severely hindered by the pore walls. Additionally, $\mathrm{LiBH}_{4}$, while decomposing, releases gaseous and toxic diborane $\left(\mathrm{B}_{2} \mathrm{H}_{6}\right)$ that at high temperatures further decomposes in $\mathrm{B}$ and $\mathrm{H}_{2}$, while it can also react with $\mathrm{LiBH}_{4}$ to generate stable closoboranes such as $\mathrm{Li}_{2} \mathrm{~B}_{10} \mathrm{H}_{10}$ and $\mathrm{Li}_{2} \mathrm{~B}_{12} \mathrm{H}_{12}$, with a direct negative effect on the overall capacity [31-33] as already mentioned. In this respect, the improved reversibility of the LiK/CMK-3 system may be related to the fact that in small pores the release of diborane is suppressed or drastically reduced $[34,46]$. 
It should be finally noted that nanoconfinement is related with significant gravimetric and volumetric penalties, since the scaffold is inert. In our case, the bulk density of the composite material for $60 \%$ loading of TPV is $0.97 \mathrm{~g} / \mathrm{cm}^{3}$ (i.e., the LiK apparent density is $0.37 \mathrm{~g} / \mathrm{cm}^{3}$ compared to $0.86 \mathrm{~g} / \mathrm{cm}^{3}$ of bulk $\mathrm{LiK}$ ) leading to $62 \%$ gravimetric and $57 \%$ volumetric penalties. However, the possibility to achieve $100 \%$ TPV loading can minimize the penalties to $49 \%$ and $28 \%$, respectively (the bulk density of the composite is then $1.21 \mathrm{~g} / \mathrm{cm}^{3}$ ).

\section{Conclusions}

The melt infiltration of a $\mathrm{LiBH}_{4} / \mathrm{KBH}_{4}$ eutectic mixture in an ordered mesoporous carbon of CMK-3 type (pore diameter $\sim 5 \mathrm{~nm}$ ) led to the development of a composite system with improved hydrogen storage properties. Pore confinement resulted in a substantial decrease of the decomposition temperature (more than $100 \mathrm{~K}$ ) of the starting borohydride mixture. Interestingly, the composite system also showed a constant uptake of $\mathrm{H}_{2}$ as high as $2.5 \mathrm{wt} \%-3 \mathrm{wt} \%$ for at least five hydrogenation-dehydrogenation cycles, upturning to a significant degree the irreversibility of the dehydrogenation reaction of the bulk LiK mixture. This improved performance in terms of reversibility, and kinetics may be associated with the combined effect of the catalytic action of the carbon surface, the nano-sizing of borohydride particles, or the limitation of irreversible side-reactions such as those leading to the formation of diboranes and closoboranes.

Author Contributions: F.P. performed the experiments and data analysis, S.P. contributed to synthesis and characterization, G.C. co-supervised the work, T.R.J. supervised the synthesis, T.S. supervised the work. F.P., G.C. and T.S. discussed the results and prepared the final manuscript with the contribution of T.R.J. All authors have read and agreed to the published version of the manuscript.

Funding: This research received funding from the European Marie Curie Actions under the ECOSTORE grant agreement $n^{\circ} 607040$.

Conflicts of Interest: The authors declare no conflict of interest.

\section{References}

1. Sloth, M. 48 Hours To Build a Hydrogen Refuelling Station, 3 Minutes To Fuel: 10+ Years To Profit. Fuel Cells Bull. 2013, 5, 12-14. [CrossRef]

2. Lai, Q.; Paskevicius, M.; Sheppard, D.A.; Buckley, C.E.; Thornton, A.W.; Hill, M.R.; Gu, Q.; Mao, J.; Huang, Z.; Liu, H.K.; et al. Hydrogen Storage Materials for Mobile and Stationary Applications: Current State of the Art. ChemSusChem 2015, 8, 2789-2825. [CrossRef]

3. Ball, M.; Weeda, M. The hydrogen economy-Vision or reality? Int. J. Hydrog. Energy 2015, 40, 7903-7919. [CrossRef]

4. Rivard, E.; Trudeau, M.; Zaghib, K. Hydrogen storage for mobility: A review. Materials 2019, 12, 1973. [CrossRef]

5. Hirscher, M.; Yartys, V.A.; Baricco, M.; Bellosta von Colbe, J.; Blanchard, D.; Bowman, R.C.J.; Broom, D.P.; Buckley, C.E.; Chang, F.; Chen, P.; et al. Materials for hydrogen-based energy storage-past, recent progress and future outlook. J. Alloys Compd. 2020, 827, 1-39. [CrossRef]

6. Bellosta von Colbe, J.; Ares, J.R.; Barale, J.; Baricco, M.; Buckley, C.; Capurso, G.; Gallandat, N.; Grant, D.M.; Guzik, M.N.; Jacob, I.; et al. Application of hydrides in hydrogen storage and compression: Achievements, outlook and perspectives. Int. J. Hydrog. Energy 2019, 44, 7780-7808. [CrossRef]

7. Manickam, K.; Mistry, P.; Walker, G.; Grant, D.; Buckley, C.E.; Humphries, T.D.; Paskevicius, M.; Jensen, T.; Albert, R.; Peinecke, K.; et al. Future perspectives of thermal energy storage with metal hydrides. Int. J. Hydrog. Energy 2019, 44, 7738-7745. [CrossRef]

8. Mazzucco, A.; Dornheim, M.; Sloth, M.; Jensen, T.R.; Oluf, J.; Rokni, M. Bed geometries, fueling strategies and optimization of heat exchanger designs in metal hydride storage systems for automotive applications: A review. Int. J. Hydrog. Energy 2014, 39, 17054-17074. [CrossRef]

9. Yartys, V.A.; Lototskyy, M.V.; Akiba, E.; Albert, R.; Antonov, V.E.; Ares, J.R.; Baricco, M.; Bourgeois, N.; Buckley, C.E.; Bellaosta von Colbe, J.M.; et al. Magnesium based materials for hydrogen based energy storage: Past, present and future. Int. J. Hydrog. Energy 2019, 44, 7809-7859. [CrossRef] 
10. Callini, E.; Aguey-Zinsou, K.F.; Ahuja, R.; Ares, J.R.; Bals, S.; Biliškov, N.; Chakraborty, S.; Charalambopoulou, G.; Chaudhary, A.L.; Cuevas, F.; et al. Nanostructured materials for solid-state hydrogen storage: A review of the achievement of COST Action MP1103. Int. J. Hydrog. Energy 2016, 41, 14404-14428. [CrossRef]

11. Møller, K.T.; Jensen, T.R.; Akiba, E.; Li, H.-w. Hydrogen-A sustainable energy carrier. Prog. Nat. Sci. Mater. Int. 2017, 27, 34-40. [CrossRef]

12. Hirscher, M. Handbook of Hydrogen Storage; Hirscher, M., Ed.; Wiley-VCH Verlag GmbH \& Co. KGaA: Weinheim, Germany, 2010; ISBN 9783527629800.

13. Zuttel, A.; Wenger, P.; Rentsch, S.; Sudan, P.; Mauron, P.; Emmenegger, C. LiBH4 a new hydrogen storage material. J. Power Sources 2003, 118, 1-7. [CrossRef]

14. Miwa, K.; Ohba, N.; Towata, S.I.; Nakamori, Y.; Orimo, S.I. First-principles study on lithium borohydride LiBH4. Phys. Rev. B Condens. Matter Mater. Phys. 2004, 69, 245120. [CrossRef]

15. Mauron, P.; Buchter, F.; Friedrichs, O.; Remhof, A.; Bielmann, M.; Zwicky, C.N.; Züttel, A. Stability and Reversibility of LiBH 4. J. Phys. Chem. B 2008, 112, 906-910. [CrossRef]

16. Milanese, C.; Jensen, T.R.; Hauback, B.C.; Pistidda, C.; Dornheim, M.; Al, E. Complex hydrides for energy storage. Int. J. Hydrog. Energy 2019, 44, 7860-7874. [CrossRef]

17. Paskevicius, M.; Jepsen, L.H.; Schouwink, P.; Černý, R.; Ravnsbæk, D.B.; Filinchuk, Y.; Dornheim, M.; Besenbacher, F.; Jensen, T.R. Metal borohydrides and derivatives-synthesis, structure and properties. Chem. Soc. Rev. 2017, 46, 1565-1634. [CrossRef]

18. Callini, E.; Özlem Kocabas Atakli, Z.; Hauback, B.C.; Orimo, S.-I.; Jensen, C.; Dornheim, M.; Grant, D.; Cho, Y.W.; Chen, P.; Hjörvarsson, B.; et al. Complex and liquid hydrides for energy storage. Appl. Phys. A 2016, 122, 1-22. [CrossRef]

19. Møller, K.T.; Sheppard, D.; Ravnsbæk, D.B.; Buckley, C.E.; Akiba, E.; Li, H.; Jensen, T.R. Complex Metal Hydrides for Hydrogen, Thermal and Electrochemical Energy Storage. Energies 2017, 10, 1645. [CrossRef]

20. Nickels, E.A.; Jones, M.O.; David, W.I.F.; Johnson, S.R.; Lowton, R.L.; Sommariva, M.; Edwards, P.P. Tuning the decomposition temperature in complex hydrides: Synthesis of a mixed alkali metal borohydride. Angew. Chemie Int. Ed. 2008, 47, 2817-2819. [CrossRef]

21. Nakamori, Y.; Orimo, S.I. Destabilization of Li-based complex hydrides. J. Alloys Compd. 2004, 370, $271-275$. [CrossRef]

22. Paskevicius, M.; Ley, M.B.; Sheppard, D.A.; Jensen, T.R.; Buckley, C.E. Eutectic melting in metal borohydrides. Phys. Chem. Chem. Phys. 2013, 15, 19774-19789. [CrossRef]

23. Plerdsranoy, P.; Kaewsuwan, D. Effects of specific surface area and pore volume of activated carbon nanofibers on nanoconfinement and dehydrogenation of LiBH4. Int. J. Hydrog. Energy 2017, 42, 6189-6201. [CrossRef]

24. Sofianos, M.V.; Chaudhary, A.; Paskevicius, M.; Sheppard, D.A.; Humphries, T.D.; Dornheim, M.; Buckley, C.E. Hydrogen storage properties of eutectic metal borohydrides melt-infiltrated into porous Al scaffolds. J. Alloys Compd. 2019, 775, 474-480. [CrossRef]

25. Ley, M.B.; Roedern, E.; Jensen, T.R. Eutectic melting of LiBH4-KBH4. Phys. Chem. Chem. Phys. 2014, 16, 24194-24199. [CrossRef]

26. Roedern, E.; Hansen, B.R.S.; Ley, M.B.; Jensen, T.R. Effect of Eutectic Melting, Reactive Hydride Composites, and Nanoconfinement on Decomposition and Reversibility of LiBH4-KBH4. J. Phys. Chem. C 2015, 119, 25818-25825. [CrossRef]

27. De Jongh, P.E.; Adelhelm, P. Nanosizing and nanoconfinement: New strategies towards meeting hydrogen storage goals. ChemSusChem 2010, 3, 1332-1348. [CrossRef]

28. Bérubé, V.; Radtke, G.; Dresselhaus, M.; Chen, G. Size effects on the hydrogen storage properties of nanostructured metal hydrides: A review. Int. J. Energy Res. 2007, 31, 637-663. [CrossRef]

29. Shao, J.; Xiao, X.; Fan, X.; Huang, X.; Zhai, B.; Li, S.; Ge, H.; Wang, Q.; Chen, L. Enhanced hydrogen storage capacity and reversibility of LiBH4 nanoconfined in the densified zeolite-templated carbon with high mechanical stability. Nano Energy 2015, 15, 244-255. [CrossRef]

30. Xia, G.; Tan, Y.; Chen, X.; Fang, F.; Sun, D.; Li, X.; Guo, Z.; Yu, X. Oxygen-free Layer-by-Layer Assembly of Lithiated Composites on Graphene for Advanced Hydrogen Storage. Adv. Sci. 2017, 4, 1600257. [CrossRef]

31. Hoang, K.; Van De Walle, C.G. Mechanism for the decomposition of lithium borohydride. Int. J. Hydrog. Energy 2012, 37, 5825-5832. [CrossRef] 
32. Friedrichs, O.; Remhof, A.; Hwang, S.J.; Zuttel, A. Role of Li2B12H12 for the Formation and Decomposition of LiBH4. Chem. Mater. 2010, 22, 3265-3268. [CrossRef]

33. Hwang, S.; Bowman, R.C.; Reiter, J.J.W.; Rijssenbeek, J.; Soloveichik, G.L.; Zhao, J.; Kabbour, H.; Ahn, C.C. NMR Confirmation for Formation of $\left[\mathrm{B}_{12} \mathrm{H}_{12}\right]_{2}$-Complexes during Hydrogen Desorption from Metal Borohydrides. J. Phys. Chem. C 2008, 112, 3164-3169. [CrossRef]

34. Surrey, A.; Bonatto Minella, C.; Fechler, N.; Antonietti, M.; Grafe, H.; Schultz, L. Improved hydrogen storage properties of $\mathrm{LiBH}_{4}$ via nanoconfinement in micro- and mesoporous aerogel-like carbon. Int. J. Hydrog. Energy 2016, 41, 5540-5548. [CrossRef]

35. Zhang, J.; Zhu, Y.; Lin, H.; Liu, Y.; Zhang, Y.; Li, S. Metal Hydride Nanoparticles with Ultrahigh Structural Stability and Hydrogen Storage Activity Derived from Microencapsulated Nanoconfinement. Adv. Mater. 2017, 29, 1-6. [CrossRef]

36. Aguey-Zinsou, K.-F.; Ares-Fernández, J.-R. Hydrogen in magnesium: New perspectives toward functional stores. Energy Environ. Sci. 2010, 3, 526-543. [CrossRef]

37. Guo, Z.X.; Aguey-zinsou, K.F. Effects of different carbon materials on $\mathrm{MgH}_{2}$ decomposition. Carbon N. Y. 2008, 46, 126-137.

38. Adelhelm, P.; Jongh, P.E. De The impact of carbon materials on the hydrogen storage properties of light metal hydrides. J. Mater. Chem. 2011, 21, 2417-2427. [CrossRef]

39. Xia, G.; Tan, Y.; Chen, X.; Sun, D.; Guo, Z.; Liu, H.; Ouyang, L.; Zhu, M.; Yu, X. Monodisperse Magnesium Hydride Nanoparticles Uniformly Self-Assembled on Graphene. Adv. Mater. 2015, 27, 5981-5988. [CrossRef]

40. Lee, J.; Kim, J.; Hyeon, T. Recent progress in the synthesis of porous carbon materials. Adv. Mater. 2006, 18, 2073-2094. [CrossRef]

41. Jun, S.; Joo, S.H.; Ryoo, R.; Kruk, M.; Jaroniec, M.; Liu, Z.; Ohsuna, T.; Terasaki, O. Synthesis of new, nanoporous carbon with hexagonally ordered mesostructure. J. Am. Chem. Soc. 2000, 122, 10712-10713. [CrossRef]

42. Huot, J.; Cuevas, F.; Deledda, S.; Edalati, K.; Filinchuk, Y.; Grosdidier, T.; Hauback, B.C.; Heere, M.; Jensen, T.R.; Latroche, M.; et al. Mechanochemistry of Metal Hydrides: Recent Advances. Materials 2019, 12, 2778. [CrossRef] [PubMed]

43. Kim, K.C.; Sholl, D.S. Crystal Structures and Thermodynamic Investigations of $\left.\mathrm{LiK}_{(\mathrm{BH}}\right)_{2}, \mathrm{KBH}_{4}$, and $\mathrm{NaBH}_{4}$ from First-Principles Calculations. J. Phys. Chem. C 2010, 114, 678-686. [CrossRef]

44. Sartori, S.; Knudsen, K.D.; Zhao-Karger, Z.; Bardaij, E.G.; Fichtner, M.; Hauback, B.C. Small-angle scattering investigations of Mg-borohydride infiltrated in activated carbon. Nanotechnology 2009, 20, 505702. [CrossRef] [PubMed]

45. Ampoumogli, A.; Charalambopoulou, G.; Javadian, P.; Richter, B.; Jensen, T.R.; Steriotis, T. Hydrogen desorption and cycling properties of composites based on mesoporous carbons and a $\mathrm{LiBH}_{4}-\mathrm{Ca}\left(\mathrm{BH}_{4}\right)_{2}$ eutectic mixture. J. Alloys Compd. 2015, 645, S480-S484. [CrossRef]

46. Liu, X.; Peaslee, D.; Jost, C.Z.; Baumann, T.F.; Majzoub, E.H. Systematic pore-size effects of nanoconfinement of LiBH4: Elimination of diborane release and tunable behavior for hydrogen storage applications. Chem. Mater. 2011, 23, 1331-1336. [CrossRef]

(C) 2020 by the authors. Licensee MDPI, Basel, Switzerland. This article is an open access article distributed under the terms and conditions of the Creative Commons Attribution (CC BY) license (http://creativecommons.org/licenses/by/4.0/). 